\title{
CORRECTION
}

\section{Correction to: Association of vitamin D receptor gene polymorphisms with disc degeneration}

\author{
Adam Biczo $^{1,3} \cdot$ Julia Szita ${ }^{1,3} \cdot$ lain McCall ${ }^{2} \cdot$ Peter Pal Varga ${ }^{1}$ on behalf of the Genodisc Consortium · Aron Lazary ${ }^{1}$ \\ Published online: 14 January 2020 \\ (c) Springer-Verlag GmbH Germany, part of Springer Nature 2020
}

Correction to: European Spine Journal

https://doi.org/10.1007/s00586-019-06215-7

Unfortunately, the following reference was missed out in the original publication.

Toktaş ZO, Ekşi MŞ, Yılmaz B et al (2015) Association of Collagen I, IX, and vitamin D receptor gene polymorphisms with radiological severity of intervertebral disc degeneration in Southern European Ancestor. Eur Spine J 24:2432-2441

Publisher's Note Springer Nature remains neutral with regard to jurisdictional claims in published maps and institutional affiliations.

The original article can be found online at https://doi.org/10.1007/ s00586-019-06215-7.

Aron Lazary

aron.lazary@bhc.hu

1 National Center for Spinal Disorders, Kiralyhago Street 1,

Budapest 1126, Hungary

2 Department of Diagnostic Imaging, The Robert Jones \& Agnes Hunt Orthopaedic and District Hospital, Gobowen, Oswestry SY10 7AG, UK

3 Semmelweis University School of Ph.D. Studies, Ulloi Street 26, Budapest 1086, Hungary 